\title{
Muserskiy, the Brazilian Volleyball Executioner: Performance Evaluation Based in Pause-Effort Ratio in 2012 Olympic Summer Games
}

\author{
Diego Ramos Do Nascimento, Rafael Marques Garcia* and Erik Giuseppe Barbosa Pereira \\ Games Department, Federal University of Rio De Janeiro, Rio De Janeiro, Brazil
}

Submission: November 02, 2018; Published: November 15, 2018

*Corresponding author: Rafael Marques Garcia, Games Department, Brazil

\begin{abstract}
Introduction: The growth and popularization of volleyball made an increase of the sport's interest. We cannot separate de actual evolution of the sport with the evolution of the scout used for the technical understanding and with the most important physiological variable.

Objective: Evaluate the ratio of the effort time with the pause time, investigating which were the consequences of the tactical changes in this ratio.

Methods: The study characterized to be observational and cross-sectional. The data were acquired of a video and analyzed by the software SPSS for Windows, version 22.0. Results: The median of the effort time was 4"59"', the median of the normal pause time was $23^{\prime \prime} 12^{\prime \prime \prime}$ and the median of the exceptional pause time was 71"74"'. The ratio of the effort time was 1 minute to each 4,5 minutes of the pause time. Before the tactical change of the athlete Muserskiy, the ratio was 1:5,2 minutes and after this tactical change this ratio will be 1:4,7 minutes.
\end{abstract}

Conclusion: The tactical change was capable to modify the game dynamics, since the tactical aspect until the physiological, turning into faster and more intense.

Keywords: Effort-pause ratio; Volleyball; Tactical Changes; Physiological Aspects

\section{Introduction}

With the expressive results of the women and men national teams at the last decade, the Brazilian volleyball has gained notoriety and popularity among viewer and, it seems, is consider the second national sport of Brazil [1]. This growth has been given, in large scale, by the changes that happened in rules aiming a new match dynamic what can be attractive to practitioners, to crowd and the media [2]. This interest generated, parallel to the emergence and evolution of the many research's direct to, first at all, the development of the sport.One of the principal factors to the victorious campaign in the volleyball is, no doubt, the physical preparation [3]. The high investment in infrastructure and technology by the Brazilian Volleyball Confederation (CBV) makes with the specific high-performance training can be realized [4]. Allied with it, the professional capitation in this process is vital to the global success of the project [5]. About the high-performance practice of the volleyball, it's possible to understand that, to the excellent results, it is necessary that athletes have big capacity to realize explosive power actions successively and intensely, demanding a maximal anaerobic capacity [6]. This model of the physical conditioning goes through, among other variables, by the necessity of the anaerobic capacity differentiated, principally to the realization of multiple intense stimulus with small pause intervals [7].

We cannot unlink the total evolution of the volleyball with the scout evolution objectifying the knowledge of the technical part and the physiological variables needed to practice in high performance [8]. This scout can be revealed by the real match idea, avoiding the omission of the information that are so important to the performance evaluation of the player or team [9]. Among the principal information extracted by the scout, we can quote the effort time (ET) basically understood between rally time (RT) and the pause time (PT), subdivided in routine stoppage time (RST) -the natural pauses in the game, for example, the interval between a point and the next volleyball service -and exceptional stoppage time (EST) -every pause due to especial situations, resting times and replacements [10].The volleyball game can have your characteristics changed according to technical or player interventions. The tactical modulations, with efficacy or not, have significant role showed in the dynamic of the game [11]. So, the aim of this study was to evaluate the effort-pause ratio, investigating the consequences of the tactical changes in this ratio in the Olympic Final between men, at London, 2012. 


\section{Methodology}

This is a crossed observational study, because it did not manipulate the data to obtain the expected results [12]. The measurement to effort time (ET) and pauses time (PT) was retired of the video in streaming web site.To evaluate the effort and pause time was used a timer (Speedo -Model 10ATM). The ET it occurred since the hit of the player in volleyball service until the point. The PT was obtained in the moment of the point until the new volleyball service. Otherwise, the EST was measured in all pauses resulting of the special facts like the rest of the time out, technical time out, also called television time out, and the referee time out [10].The data analyses were made throw software
SPSS for Windows, version 22.0. Beyond the total time values, we calculated the median of the measures due to results of the coefficient of variation.3. Analysis and Discussion The time found in this match is within the literature in reference of total duration between 2 or 3 hours in the match in high performance [13]. This author found, in the final of Men's America Cup in 2005, disputed in 5 sets, an ET median value of 4"96"', similar with the exposed in the next (Tables 1\&2). The same author found in the final of PanAmerican Championship, ET median value of 4"75"', also similar, even considering that match had 3 sets.The values found in the first set are similar medium values found in the researches of Vieira e Fernandes Filho [10] and Esper [14] for the effort-pause time ratio of the match.

Table 1: Total effort and pause time.

\begin{tabular}{|c|c|c|c|c|c|c|}
\hline & 1o Set & 2o Set & 3o Set & 4o Set & 5o Set & Game \\
\hline Total Score & 44 & 45 & 56 & 47 & 24 & 216 \\
\hline E.T (Min) & $3^{\prime} 59^{\prime \prime}$ & $3^{\prime} 58^{\prime \prime}$ & $6^{\prime} 18^{\prime \prime}$ & $3^{\prime} 47^{\prime \prime}$ & $3^{\prime} 01^{\prime \prime}$ & $21^{\prime} 03^{\prime \prime}$ \\
\hline R.S.T (Min) & $15^{\prime} 03^{\prime \prime}$ & $16^{\prime} 24^{\prime \prime}$ & $19^{\prime} 50^{\prime \prime}$ & $15^{\prime} 26^{\prime \prime}$ & $7^{\prime} 35^{\prime \prime}$ & $7^{\prime} 08^{\prime \prime}$ \\
\hline E.S.T (Min) & $6^{\prime} 14^{\prime \prime}$ & $6^{\prime} 23^{\prime \prime}$ & $7^{\prime} 20^{\prime \prime}$ & $8^{\prime} 15^{\prime \prime}$ & $7^{\prime} 15^{\prime \prime}$ & $31^{\prime} 29^{\prime \prime}$ \\
\hline Total Time (Min) & $216^{\prime \prime}$ & $26^{\prime} 45^{\prime \prime}$ & $33^{\prime} 28^{\prime \prime}$ & $27^{\prime} 28^{\prime \prime}$ & $1^{\prime} 53^{\prime \prime}$ & $126^{\prime} 40^{\prime \prime}$ \\
\hline
\end{tabular}

Table 2: Medians of ET and PTs.

\begin{tabular}{|c|c|}
\hline E.T & $4 " 59^{\prime \prime}$ \\
\hline R.S.T & $23{ }^{\prime \prime} 12^{\prime \prime}$ \\
\hline E.S.T & $714^{\prime \prime \prime}$ \\
\hline
\end{tabular}

To the second set we found an ET/PT ratio bigger than the first one and a small total score from Muserskiy for a player who plays as middle hitter, in according with the study conducted by Junior [15].In the third set was occurred a tactical change with Muserskiy. It's notable that in this set happened a reduction in values of ET/PT ratio and an increase of points from Muserskiy. In the fourth set, was found the bigger ET/PT ratio because happened an excessive number of stoppages, what can explain this discrepancy in comparative at the previous set. The Table 3, besides revealing this ratio, shows the evolution of Muserskiy in the match: although with a small score in the fourth set, he rises as the biggest striker in this match.In the decisive set, it was clear and explicit the effects of the tactical change in the match intensity, demonstrated in the ET/PT ratio smaller, besides the overview of Muserskiy's score, that kept evaluating, once he made $27 \%$ of the total set points of Russian's team.Although the demonstration

of the change of match dynamic, when analyzed the percentage values of duration of effort time and pause-time, explicit in Table 4 , it was found a pause time of $83,36 \%$ and effort time of $16,64 \%$. Other researches $[10,14]$ founded a similar percentage compared with these results. This general characteristic similar toother researches point out the discussion about energetic ways utilized during the volleyball match, considering that the increase of intensity makes an anaerobic threshold potentialized, the aerobic bias of the match had little change due to total duration. This duality shows the needed of a differenced periodization, providing in athlete the capacity of growing your resistance, both aerobic and anaerobic, turned to actual volleyball demand.

Table 3: Effort-time ratio and Muserskiy sets score.

\begin{tabular}{|l|c|c|c|}
\hline & Effort-Pause Ratio (Min) & Score & Tactical Position \\
\hline Set $\mathbf{1}$ & $1-5,2$ & 3 & Middle Hitter \\
\hline Set $\mathbf{2}$ & $1-5,4$ & 3 & Middle Hitter \\
\hline Set $\mathbf{3}$ & $1-4,1$ & 17 & Opposite \\
\hline Set $\mathbf{4}$ & $1-6,1$ & 5 & Opposite \\
\hline Set $\mathbf{5}$ & $1-3,4$ & 4 & Opposite \\
\hline
\end{tabular}

Table 4: Percentage of effort time and pause time.

\begin{tabular}{|c|c|c|c|c|c|c|}
\hline & 1' Set & 20 Set & 3o Set & 4o Set & 5o Set & Game \\
\hline E.T (\%) & $16 \%$ & $15,40 \%$ & $18,57 \%$ & $12,72 \%$ & $22,25 \%$ & $16,64 \%$ \\
\hline R.S.T (\%) & $60 \%$ & $61,40 \%$ & $58,59 \%$ & $55,94 \%$ & $54,32 \%$ & $58,61 \%$ \\
\hline E.S.T (\%) & $24 \%$ & $23,20 \%$ & $22,84 \%$ & $31,34 \%$ & $23,43 \%$ & $24,75 \%$ \\
\hline Total Time (Min) & $25^{\prime} 16^{\prime \prime}$ & $26^{\prime} 45^{\prime \prime}$ & $33^{\prime} 28^{\prime \prime}$ & $27^{\prime} 28^{\prime \prime}$ & $13^{\prime} 53^{\prime \prime}$ & $126^{\prime} 40^{\prime \prime}$ \\
\hline
\end{tabular}


The Table 5 shows the effort-pause ratio total and subdivided in after and before of the change of position of DimitriyMuserskiy. In set 1 and 2 this player acted as middle hitter and, in the other ones, acted as opposite.The total effort-pause ratio of the match was 1:4,5 minutes, this result was a little different of the research of Vieira and Fernandes Filho [10] -1:5,5 minutes. The new tactical position of Muserskiy changed not only the result of the match, once the Russian's team reverted the game score after this tactical modification, but also changed the effort-pause ratio of the match. Before this tactical modification, the effort-pause ratio was 1:5,2 minutes, while after the effort-pause ratio went to $1: 4,7$ minutes. The reduction in this ratio has direct reflex in the predominant energetic system, because the anaerobic system turned in predominant way in this moment [16].It's relevant emphasize when match was 2x0 for Brazil (25X19 and 25X20), Muserskiy was acting as middle hitter, scoring only 6 points. In the beginning of the third set, this athlete started acting as opposite hitter and Russian's team, with your giant of 7'15" ft., started a historical reverse. The Brazilian executioner scored 25 points of the 65 Russian's team points in the last 3 sets $(27 X 29,22 X 25$ and 9X15), totalizing 31 points of 108 scored by the team. This total score gives, beyond the title to your nation, the record of the highest scorer in the Olympic Finals and the title of better striker in this competition, elected by Fédération Internationale de Volleyball (FIVB).

Table 5: Effort-Pause ratio with the tactical changes.

\begin{tabular}{|c|c|c|}
\hline Ratio Total & Muserskiy as Middle Hitter & Muserskiy as Opposite \\
\hline $1-4,5$ & $1-5,2$ & $1-4,7$ \\
\hline
\end{tabular}

\section{Conclusion}

It's possible to concluded, therefore, that the strategical modification could change significantly the dynamic of the match since the tactical characteristic, once the Brazilian defensive system had extreme difficult to comprehend the tactical reader of the match, until the physiologic characteristics of the match, because the decrease of effort-pause ratio interfere directly in the major use of anaerobic system, given that the points are faster when the recuperation pauses are smaller.This study suggests the conducting of further researches making possible a broad discussion about this theme. The research continuation is necessary due to change in the rules aiming the evolution of the match dynamic, for example, the decrease of time between the point and the new volleyball service.Although of the endeavor of speed up the volleyball matches, this research reveals the existence of gaps between match dynamic and physical, physiological and tactical preparation.

\section{References}

1. Moreira TS, Ferreira ALP, Marchi W (2007) The professionalization of women's volleyball in Brazil - the case of athlete Jaqueline Silva. X International Civilizing Process Symposium. Unicamp, Campinas SP, Brazil.

2. Bompa TO (2010) Coaching Athletes of Collective Sports. São Paulo: ED. Phorte.

3. Tubino MG (1993) Scientific Methodology of Sports Training. $11^{\text {th }}$ ed. São Paulo: Ibrasa.

4. Souza SL(2007) The importance of the organizational strategy for the Brazilian confederation of volleyball. Rev. Contemporary Thought in Administration. Rio de Janeiro, v1no 1. set./dez 116-125117.

5. Graça Filho AS, Kasznar IK(2002) Sport as an industry: a solution for the creation of wealth and employment. Rio de Janeiro: Brazilian Volleyball Confederation.

6. Borsari JR (2001) Volleyball: learning and training. $3^{\text {rd }}$ edn. São Paulo: EPU.

7. Vimieiro-Gomez AC, Rodrigues LOC (2011) Evaluation of athletes' hydration status, thermal stress of the environment and caloric cost of the exercise during high-level volleyball training sessions. Journal of Physical Education, São Paulo 15(2): 201-211.

8. Zamberlam AO, Wives LK, Goulart RRV, Silveira RGA (2005) was entering the volleyball court: Smart Scout. Hifen Review29(55): 103110.

9. Balieiro S(2004) High tech game. Info: information technologynumber 224(19).

10. Vieira GCF, Fernandes Filho J(2010) Quantitative parameters of timeless jumps of effort and pause in adult male volleyball. Rev.Dig. Physical Education Sports15(144): 1-7.

11. Anfilo MA (2003) The pedagogical practice of the coach of the Brazilian men's volleyball team: A process of tactical and technical evolution in the child-youth category. UFSC - Brazil.

12. Thomas JR, Nelson K(2002) Research methods in physical activity; trad. Ricardo Petersen, $3^{\text {rd }}$ edition; Porto Alegre - RS - Brazil.

13. Vieira GCF(2006) Total playing time of the match between Brazil and the United States in the final of the American Men's Volleyball Adult Cup; FIEP BulletinSpecial Edition 76: 73.

14. Esper A (2003) Playing times and pause in women's and men's volleyballEF SportsRevista Digital - Buenos Aires - Year 9 - N ${ }^{\circ} 64$ -September.

15. Junior NKM(2011) Score prediction of the high-profile male volleyball striker. Physical Education in a Journal ISSN: 1983-6643, 5 №3

16. Vergara CMS, Salfran YF. Resistance as conditional ability in volleyball. Readings: Physical education and sport. 
This work is licensed under Creative Commons Attribution 4.0 License

DOI: 10.19080/JPFMTS.2018.05.555670

\section{Your next submission with Juniper Publishers} will reach you the below assets

- Quality Editorial service

- Swift Peer Review

- Reprints availability

- E-prints Service

- Manuscript Podcast for convenient understanding

- Global attainment for your research

- Manuscript accessibility in different formats ( Pdf, E-pub, Full Text, Audio)

- Unceasing customer service

Track the below URL for one-step submission https://juniperpublishers.com/online-submission.php 